\title{
Internet of Things based Smart Energy Management for Smart Home
}

\author{
Mehmet TAȘTAN \\ Department of Electronics \& Automation, Manisa Celal Bayar University, \\ 45000, Manisa, Turkey \\ [mehmet.tastan@cbu.edu.tr]
}

Received October 31, 2018; revised December 6, 2018; accepted December 24, 2018;

published June 30, 2019

\begin{abstract}
Thanks to internet, as one of indispensable parts of our lives, many devices that we use in our daily lives like TV, air conditioner, refrigerator, washing machine, can be monitored and controlled remotely by becoming more intelligent via Internet of Things (IoT) technology. Smart Home applications as one of the elements of smart cities, are individually the most demanded application without question. In this study, Smart Energy Management (SEM) system, based on NodeMCU and Android, has been designed for SEM, which is a part of the smart home application. With this system, household energy consumption can be monitored in real time, as well as having the ability to record the data comprising of operation times and energy consumption information for each device. Additionally, it is ensured to meet the energy needs on a maximized level possible, during the hours when the energy costs are lower owing to the SEM system. The Android interface provides the users with the opportunity to monitor and change their electricity consumption habits in order to optimize the energy efficiency, along with the opportunity to draw up of a daily and weekly schedule.
\end{abstract}

Keywords: Internet of things, NodeMCU, android, smart energy management, smart home. 


\section{Introduction}

IoT is a term, which was first suggested by Kevin Ashton in 1999 [1]. IoT is a communication network where the objects are connected to each other or to larger systems. This network converts billions of data, obtained from various devices that we use in our daily lives, into usable information [2]. According to CISCO report, while there were 500 million interactive devices in 2003, it is estimated to be 50 billion by 2020 [3]. This shows that the cities, where we live with IoT, will turn into smart cities keeping pace with more energetic and planned lives [4]. This conversion will also offer many opportunities to us for making our lives easier [5]. Smart Home is a term that is widely used in order to define a living space with lighting, heating, air conditioner, TV, computer, entertainment, audio-visual systems, security and camera system that can communicate with each other [6]. It is placed in the center of our lives with regards to many areas like the TV, audio-visual system in our houses to run once we get home, lighting and electrical devices to be controlled remotely [7], heating system to run via our cell phones by receiving location details [8], as well as making adjustments automatically based on the regional weather conditions [9], monitoring and controlling the power consumption of such devices as refrigerator, air conditioner, furnace, etc. [10], garden irrigation process to be carried not based on the time, but on the humidity level of the soil [11], patients that require continuous monitoring to have a safer life with wearable medical devices [12], smart farms practices [13] and smart grids [14].

In this study, our objective is to reduce the energy consumption with a proper operation planning, by monitoring the energy consumption of a house. In line with this objective, an IoT-based smart energy consumption monitoring and energy management system has been designed. Thanks to the system with Android interface, user can get consumption information of all electrical devices in the household instantly. Using the dish washer, washing machine and dryer, which has the flexibility to be used during the day, to be operated as planned before and during the hours with lower energy costs, helps reducing the energy costs. The energy consumption data for each and every device, which are used with this application, can be taken under record. Owing to this, the measures to be taken for ensuring energy saving will be even easier. It allows the Android interface users, to have the ability to control the devices in their houses via remote access. Additionally, android application has the ability to send notifications via e-mail, twitter, etc. for pre-designated failure codes like over-current, short-circuit, over-temperature and power cut-off, along with such real time data for the devices as current, voltage and power.

The main contribution of this study is presented below.

- Designed as an IoT-based SEM system for home energy management, which is part of smart grids.

- With SEM system, operating hours of electrical household appliances are programmed, considering user comfort and PAR value.

- Having flexible operating hours, loads such as washing machines, dishwashers are shifted to periods where energy costs are low. Therefore, total amount of energy and energy cost is reduced.

- The operating conditions of the electrical household (active, passive, fault etc.) can be monitored in real time via the android based user interface. 
- The operating parameters (current, voltage, power etc.) of the electrical appliances used are continuously recorded in the cloud system. In this way, additional measures can be taken to reduce the energy cost by using backward working information.

The rest of the paper is organized as follows: In Section 2, we discuss the related work. The software and hardware of the SEM system are introduced in Section 3. The architecture of the system is introduced in Section 4. Results and discussions are presented in Section 5. Finally, the paper findings are presented in Section 6.

\section{Related Work}

In the following we describe the related works on energy management system in smart homes. Smart grids has become one of the main subjects of IoT application in the recent years, thus attracting immense attention [15]. Smart grids is a hope-inspiring technology for dealing with continuously increasing power consumption [16]. Smart grid has created a network of information and communication technologies that allow bidirectional communication between consumers and the network, unlike traditional grid that face many challenges, such as old infrastructure, increased energy demand and security issues. In general, the smart grid is emerging as a new generation grid and includes communication, distributed production, cyber security, advanced measurement infrastructure and technologies [17]. The main purpose of the smart grid is to convert conventional grid into a cost effective and energy efficient electricity grid. The home energy management system (HEMS), which is a part of the smart grid, makes a major contribution to the planning of the operation of household appliances and to the reduction of electricity consumption [18]. Demand-side management (DSM) is an important component of the smart grid's energy management. In general, DSM refers to managing the consumer's energy use in such a way as to achieve the desired changes in the load profile [19]. Demand response (DR), which is one of the DSM activities, is defined as the tariffs or programs determined to optimize the energy consumption profiles of the latest users [20]. The DR is considered to be an important feature in the smart grid to improve the sustainability and reliability of the grid. DR consists of two programs: incentive and price-based. An incentive-based program provides the latest-user incentives on the basis of load reduction. On the other hand, a price-based program reduces both the cost and the Peak-to-average ratio (PAR) by reducing energy use in periods of high electricity price [21]. In [22], authors propose a smart power socket and central control system that utilizes the Zigbee communication protocol to control energy usage. Experimental results show that the proposed smart socket can correctly read the power consumption of wirelessly connected devices from up to $18 \mathrm{~m}$ away without loss of data. The work in [23], presents an algorithm for home energy management system to shift the schedulable loads in a residential home, that satisfies consumer comfort and minimizes electricity bill of energy consumption using Hourly-Time-Of-Use (HToU) pricing scheme. The authors in [24], propose a multi-power-based building energy management system (MPBEMS) for efficient energy management in buildings. Thanks to the proposed energy estimation model, an energy saving of $5 \%$ is achieved annually. In [25], the authors conducted a study using Fuzzy logic and heuristic optimization techniques, taking into account the PAR and user comfort (UC). Simulation results show a significant reduction in energy consumption, cost and PAR. The work in [26], comparatively evaluate the performance of home energy management controller which is designed to plan the energy consumption on the basis of heuristic algorithms with genetic algorithm (GA), binary particle swarm optimization (BPSO) and ant colony optimization (ACO). Simulation results show that all designed models for energy management 
act significantly to achieve our objections and proven as a cost-effective solution to increase sustainability of smart grid.

The work in [27], HEMS is proposed to allow individual smart household device interaction with data collecting module in the form of IoT. This motivates consumers to locally monitor and control devices, and online costing generation by means of a mobile web mobile application. The authors in [28], propose the wind-driven optimization (WDO) algorithm. Simulation results show that proposed hybrid WDO algorithm performs better than the other heuristic algorithms in terms of the selected performance metrics. In [29], real time optimal schedule controller for HEMS is proposed using a new binary backtracking search algorithm (BBSA) to manage the energy consumption. The proposed algorithm is compared with the binary particle swarm optimization (BPSO) to determine the accuracy of the proposed controller in HEMS. Table 1 shows the summary of the literature.

Table 1. Summary of related work.

\begin{tabular}{|c|c|c|c|}
\hline Techniques & $\begin{array}{l}\text { Targeted } \\
\text { Area }\end{array}$ & Objectives & $\begin{array}{l}\text { Pricing } \\
\text { Schemes }\end{array}$ \\
\hline GHSA [17] & HEMS & $\begin{array}{l}\text { Minimizes electricity cost, PAR and maximizes } \\
\text { the user comfort }\end{array}$ & $\begin{array}{l}\text { RTP and } \\
\text { CCP }\end{array}$ \\
\hline $\begin{array}{l}\text { BAT, FP, HFBA } \\
\text { algorithms [25] }\end{array}$ & HEMS & Total energy cost minimization, PAR reduction & - \\
\hline $\begin{array}{l}\text { GA, BPSO, ACO } \\
\text { algorithms [26] }\end{array}$ & HEMS & $\begin{array}{c}\text { Cost and PAR reduction by satisfying user } \\
\text { comfort }\end{array}$ & $\begin{array}{l}\text { ToU and } \\
\text { IBR }\end{array}$ \\
\hline IoT [27] & HEMS & $\begin{array}{c}\text { Motivates users to locally monitor and control } \\
\text { devices }\end{array}$ & - \\
\hline $\begin{array}{l}\text { GA, BPSO, BFOA, } \\
\text { WDO, GWD [28] }\end{array}$ & HEMS & $\begin{array}{l}\text { Reduces the energy consumption, electricity cost } \\
\text { and achieves energy savings for week days and } \\
\text { weekend }\end{array}$ & RTP \\
\hline $\begin{array}{l}\text { BBSA, BPSO } \\
\text { algorithms [29] }\end{array}$ & HEMS & $\begin{array}{l}\text { Reduces the energy consumption and electricity } \\
\text { cost }\end{array}$ & - \\
\hline $\begin{array}{c}\text { WDO, PSO } \\
\text { algorithms [30] }\end{array}$ & HEMS & $\begin{array}{c}\text { Cost and PAR Reduction,User Comfort } \\
\text { Maximization }\end{array}$ & - \\
\hline $\begin{array}{c}\text { Q-learning } \\
\text { algorithm [31] }\end{array}$ & HEMS & $\begin{array}{l}\text { Reduces the energy consumption and electricity } \\
\text { cost }\end{array}$ & - \\
\hline $\begin{array}{l}\text { Dijkstra algorithm } \\
\text { [32] }\end{array}$ & HEMS & $\begin{array}{l}\text { Minimizes the total cost, trades the } \\
\text { computational complexity for lower } \\
\text { performance }\end{array}$ & ToU \\
\hline MILP [33] & HEMS & Minimizes the total electricity cost & ToU \\
\hline G-DSM [34] & HEMS & $\begin{array}{l}\text { Total energy cost minimization, PAR reduction, } \\
\text { and Waiting Time of Appliances (WTA) }\end{array}$ & RTP \\
\hline
\end{tabular}

In [30], authors have proposed an energy demand management model based on the WDO and PSO algorithms to reduce the electricity bill and high PAR by preserving the user comfort 
within acceptable limits. The proposed algorithm in [31] reduces the average energy costs by delaying the operating time of the energy consuming devices, delaying their operations or predicting their future use and operating them earlier. The work in [32], presented a framework for scheduling the home appliances in limited scheduling hours with lower computational complexity and minimal overall cost without disturbing the operation of non-scheduleable devices. In study [33], the authors presented the proposed distributed home energy management optimization algorithm using the mixed integer linear programming (MILP) in the time of use (TOU) pricing tariff where the electricity price varies according to a different time block. In [34], a Generic Demand Side Management (G-DSM) model is proposed that reduces PAR, energy cost and Waiting Time of Appliances (WTA) for residential users.

\section{Materials and Methods}

Many of the devices we use today, where the technology age is experiencing very fast, can be easily monitored and controlled from remote, especially with smart phones and tablets. With the increase of companies that produce embedded system microcontroller by each passing day, the prices of such products get lower day by day. However, with Android and IOS interface development programs becoming user-friendly, examples of smart applications are increasing rapidly with IoT. NodeMCU and Arduino Pro Mini microcontrollers, NRFL01 wireless communication modules for bi-directional RF communication were used for SEM system, while using ACS712-30A current and ZMPT101B voltage sensors for measuring the energy consumption.

\subsection{NodeMCU}

NodeMCU with 32 bit ESP8266-12E controller, is a module, having the ability to carry out IoT applications with lower costs. It offers digital I/O units, analog input, PWM outputs and communication support.

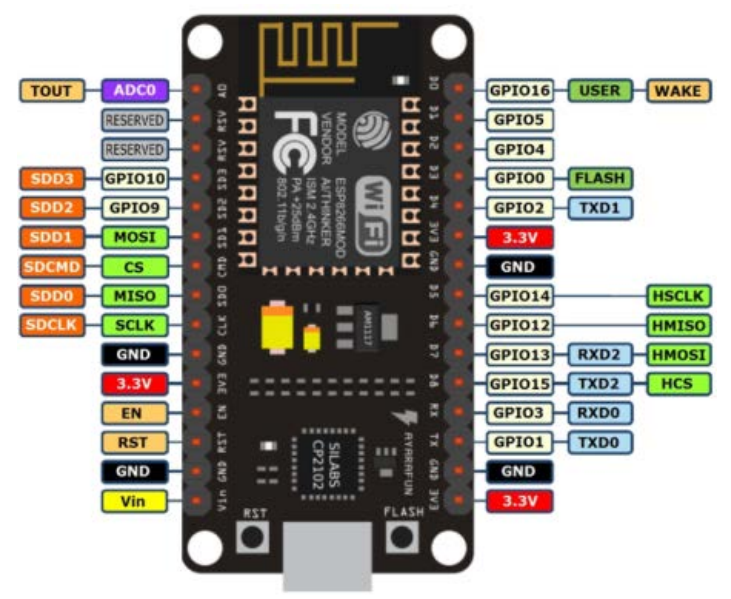

Fig. 1. NodeMCU pin structure

NodeMCU is an IoT controller having Wi-Fi module, which is widely used. "Lua" language and Arduino IDE can be used for programming NodeMCU. MicroUSB port can be used for programming, thus not requiring an additional programmer. On Fig. 1, you can see the pin 
structure of NodeMCU, while the technical specifications of NodeMCU can be seen on Table 2.

Table 2. NodeMCU technical specifications

\begin{tabular}{|c|c|}
\hline Specifications & Value \\
\hline \hline MCU & 32 bit Tensilica L106 \\
\hline Frequency & $80 / 160 \mathrm{MHz}$ \\
\hline Input/Output & $13 \times \mathrm{xIO}$ \\
\hline ADC Pin & $1 \times 10 \mathrm{bit}(1 \mathrm{~V})$ \\
\hline Operating Voltage & $3.0 \sim 3.6 \mathrm{~V}$ \\
\hline Program Memory & $4 \mathrm{MB}$ \\
\hline WiFi & IEEE $802.11 \mathrm{~b} / \mathrm{g} / \mathrm{n}$ \\
\hline Sleep Mode Current & $<10 \mathrm{uA}$ \\
\hline Standby Mode Current & $<10 \mathrm{~mA}$ \\
\hline
\end{tabular}

As can be seen in Table 2, a 32 bit RISC Tensilica Xtena LX106 microprocessor operating at $160 \mathrm{MHz}$ has $13 \mathrm{x} \mathrm{DIO}, 1 \mathrm{x} 10$ bit ADC, $4 \mathrm{MB}$ program memory, 3v3 operating voltage and IEEE $802.11 \mathrm{~b} / \mathrm{g} / \mathrm{n}$ integrated WiFi module.

\subsection{Arduino Pro Mini}

Arduino Pro Mini can be programmed by external programmer by using Rx and Tx pins. Arduino Pro Mini, small size and low cost is an 8-bit controller. In Figure 2, shows the pin structure of the arduino pro mini.

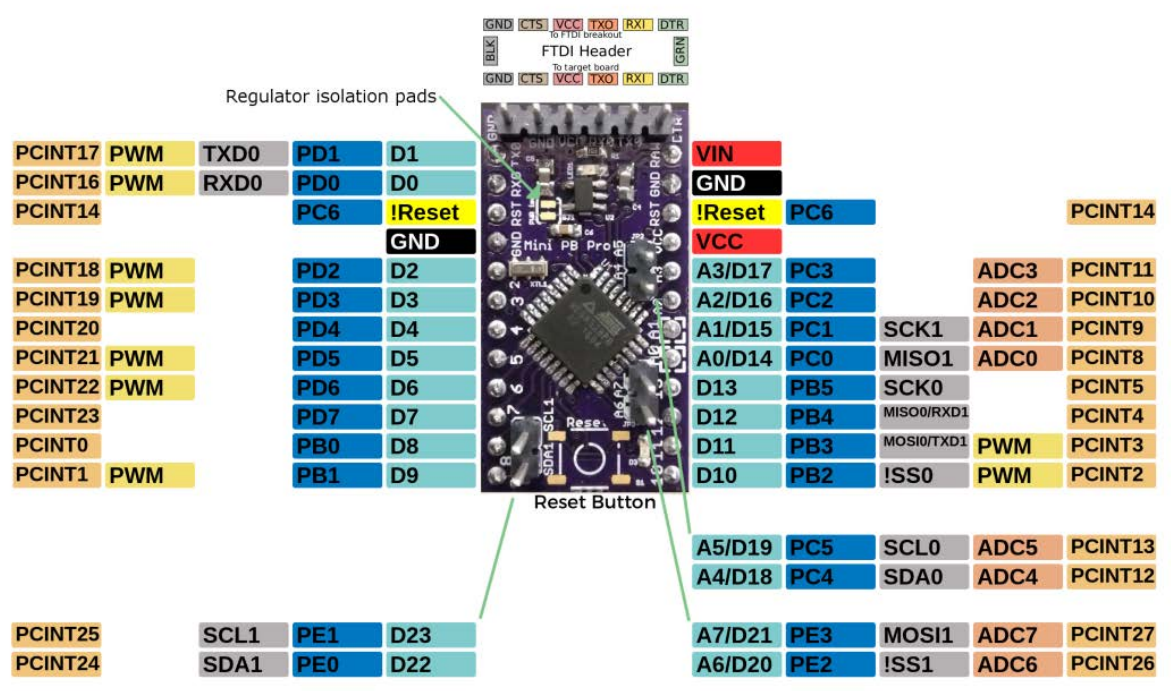

Fig. 2. Arduino Pro Mini pin structure

As in all the models of Arduino MCU, Pro Mini can be programmed with the help of Arduino IDE, as well. You can see the technical specifications of Arduino Pro Mini in Table 3. 
Table 3. Arduino Pro Mini technical specifications

\begin{tabular}{|c|c|}
\hline Specifications & Value \\
\hline \hline MCU & 8 bit ATmega328P \\
\hline Frequency & $16 \mathrm{MHz}$ \\
\hline Input/Output & $14 \times \mathrm{DIO}$ \\
\hline ADC Pin & $6 \times 10 \mathrm{Bit}$ \\
\hline Operating Voltage & $5 \mathrm{~V}$ \\
\hline IO Current & $40 \mathrm{~mA}$ \\
\hline Program Memory & $32 \mathrm{kB}$ \\
\hline
\end{tabular}

Having an 8 bit ATmega 328P processor, Pro Mini also has $16 \mathrm{MHz}$ frequency, 14 x DI/O, 6 x 10 bit ADC pins, 5V operating voltage, $40 \mathrm{~mA} \mathrm{I} / \mathrm{O}$ current and 32KB program memory.

\subsection{Current and Voltage Measurement}

In the SEM system, the current values of the devices are measured using the ACS7102 sensor. ACS7102 is an IC operating based on the Hall-Effect principle, which is developed by Allegro Company for measuring the current. Various versions are available within the measurement range of 5, 20 and 30 A. ACS712 current sensor has the ability to carry out current measurement both at AC and DC circuits. Sensor output is around $2.5 \mathrm{~V}$, where the load current (Ip) is 0A. As can be seen in Fig. 3, once the current is towards positive direction From IP+ to IP-), the output voltage starts to increase; while it decreases on the reverse direction (From IP- to IP+). The output voltage value is $66 \mathrm{mV} / \mathrm{A}$ for $30 \mathrm{~A}$ version of ACS712, used in the study. Where the current is towards positive direction, the sensor output is measured as $\left(2.5 \mathrm{~V}+66 \mathrm{mV}^{*} \mathrm{I}\right)$. In the reverse direction, it is calculated with the sensor output $\left(2.5 \mathrm{~V}-66 \mathrm{mV}^{*} \mathrm{I}\right)$ formula. The maximum measurement capacity of ACS712 current sensor is 30A, which equals to $30 \times 66 \mathrm{mV}=1980 \mathrm{mV}$. Where the current increases positively, the voltage level is $(2500 \mathrm{mV}+1980 \mathrm{mV}=4480 \mathrm{mV})$, while it is $(2500 \mathrm{mV}-1980 \mathrm{mV}=520 \mathrm{mV})$ in the reverse direction. In other words, the output voltage range is between $520-4480 \mathrm{mV}$. Since Arduino Pro Mini ADC input supports 0-5V range, AC712 sensor output can be directly connected.
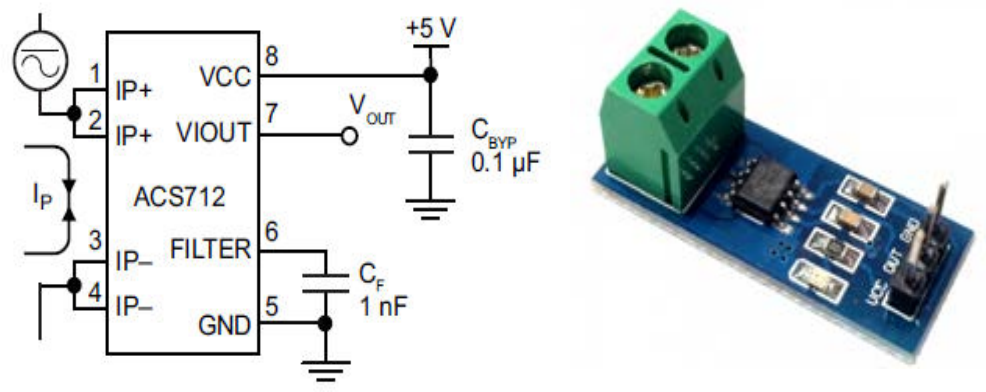

Fig. 3. ACS712-30A Current Sensor [35]

ZMPT101B voltage sensor module is a sensor, produced from the voltage transformer. Having the ability to perform high accuracy measurement, the sensor is widely used for voltage and power measurements. Using the ZMPT101B voltage sensor, measurement up to $250 \mathrm{~V}$ AC can be performed. 


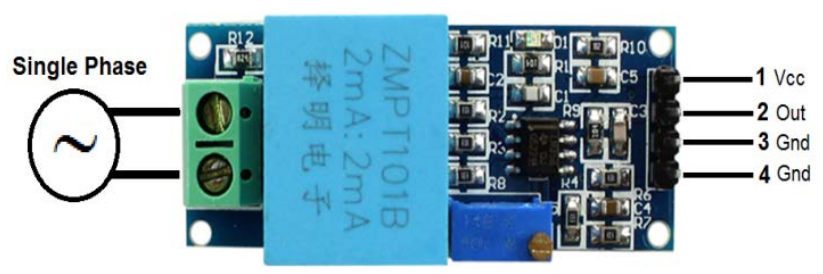

Fig. 4. ZMPT101B One-Phase Voltage Sensor

It is easy to use and it has multiturn trimpot for calibration by setting the ADC output. You can see the ZMPT101B voltage sensor module on Fig. 4. Pin 1 is Vcc-supplied, while pins 3-4 are GND. Pin 2 is the output pin, providing DC voltage output.

\subsection{Blynk (iOS and Android interface developer)}

Blynk is an iOS and Android-based application interface developer, ensuring the controlling of many controllers like Arduino, Raspery Pi and ESP8266 via internet. This program, a graphics interface can be developed for projects within the shortest period of time possible by simply using Widgets, without the need to write any code. Blynk is not dependent on a certain controller, but rather, it has the ability to operate in compatible with the controllers of various companies. It offers affordable solutions for project developers, while providing these users with the opportunity to benefit from the cloud service of Blynk, as well.

\section{System Architecture}

The structure of SEM system can be seen in Fig. 5. Basically, the system comprises of a NodeMCU controller with the ability to communicate with Blynk server via Wi-Fi, Arduino Pro Mini controller for power measurement and controlling operations, Blynk SEM interface and Blynk server, respectively.

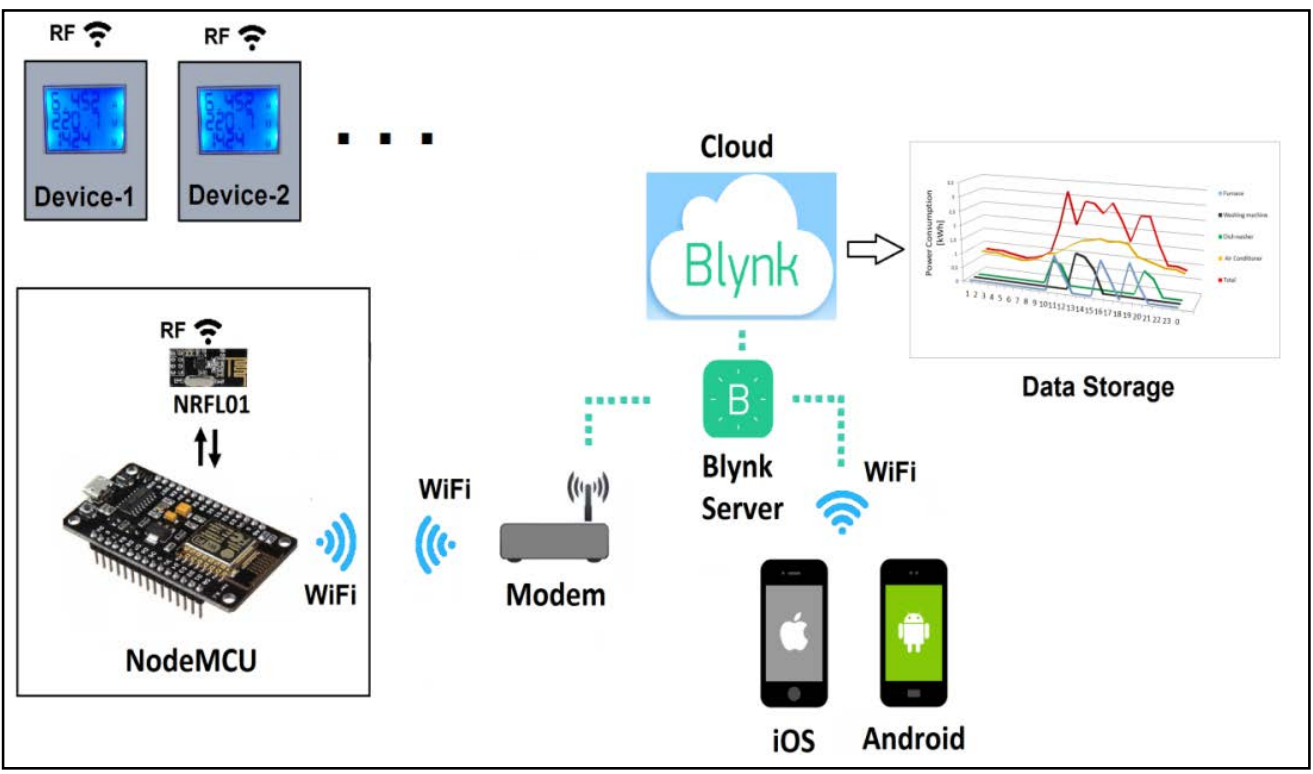

Fig. 5. The Structure of SEM system 
The code for meeting the system requirements with regards to the NodeMCU and Arduino Pro Mini controllers have been written by Arduino IDE editor. NodeMCU, with embedded Wi-Fi module, sends the current, voltage and power values received from Power Measurement and Controller Unit to Blynk server every second. The information received by NodeMCU is sent to Blynk server via local wireless network, then to Blynk interface. In Blynk application, 10-bits of data can be sent via virtual pins by using such widgets as display, terminal.

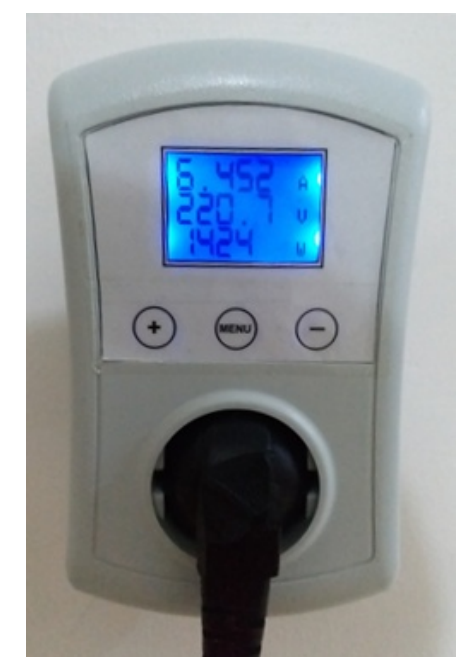

Fig. 6. Power Measurement and Controlling Module

In Fig. 6 shows the power measurement and control module. The module comprises of current-voltage sensors, NRF24L01 RF module, power supply and relay. The power consumed by the devices are calculated using the current, voltage and power coefficient values, which are measured with the sensors. These power values are displayed on the display module, while being transmitted wirelessy via RF module to NodeMCU. Additionally, the module can calculate the total energy cost, provided the unit energy cost is entered. Entering the nominal current and voltage values of the device connected to the module, the device is ensured to be protected against over-current and voltage fluctuations. This protection process is carried out by cutting-off of the device power via the relay over the module.

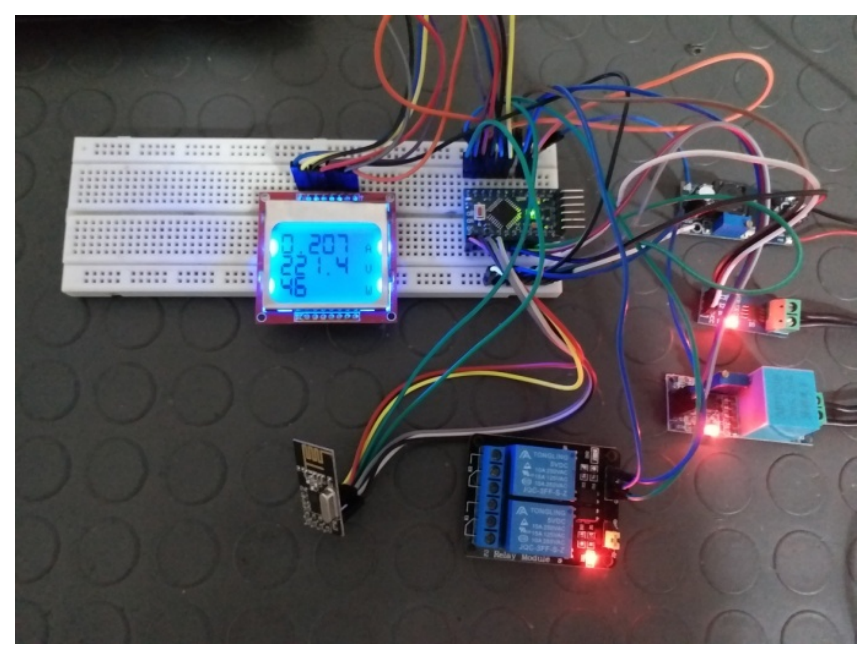

Fig. 7. Power Measurement and Controlling Module testing phase. 
In Fig. 7, you can see the on-board installation of power measurement and controlling module, including the images from the testing phase. First, the module is installed over a board, then performing current and voltage calibrations by being subjected to tests on various current and voltage levels.

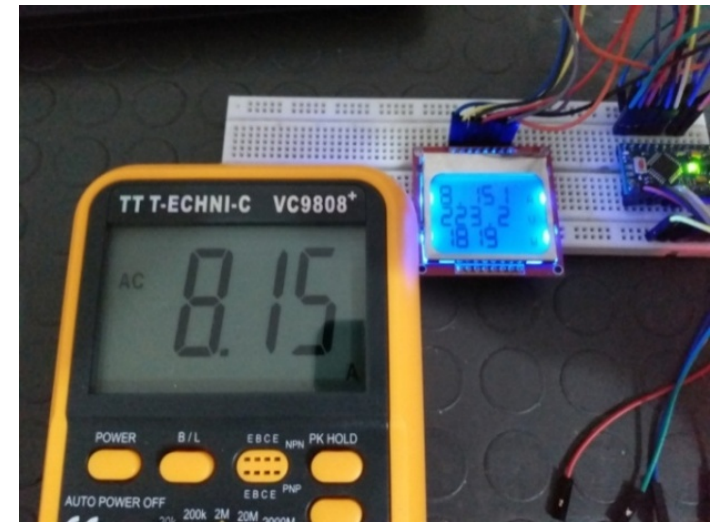

(a)

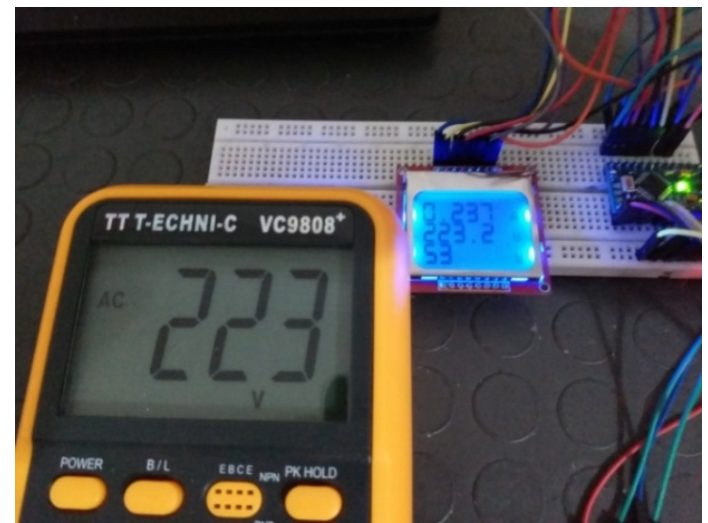

(b)

Fig. 8. (a) current, (b) voltage calibration processes for Power Measurement and Controller Device.

In Fig. 8, the images of current and voltage calibration can be seen. The measured current value of the current sensor after calibration is $8.151 \mathrm{~A}$, while the current value measured by the respective meter is 8.15, as can be seen in Fig. 8a. The post-calibration current value measured by the voltage sensor is $223.2 \mathrm{~V}$, while it is measured as $223 \mathrm{~V}$ by the respective meter, as can be seen in Fig. 8b. The calibration process carried out for the current sensor is carried out via software. The calibration of the voltage sensor, on the other hand, is performed both via software and hardware, with the multiturn trimpot placed on the sensor.

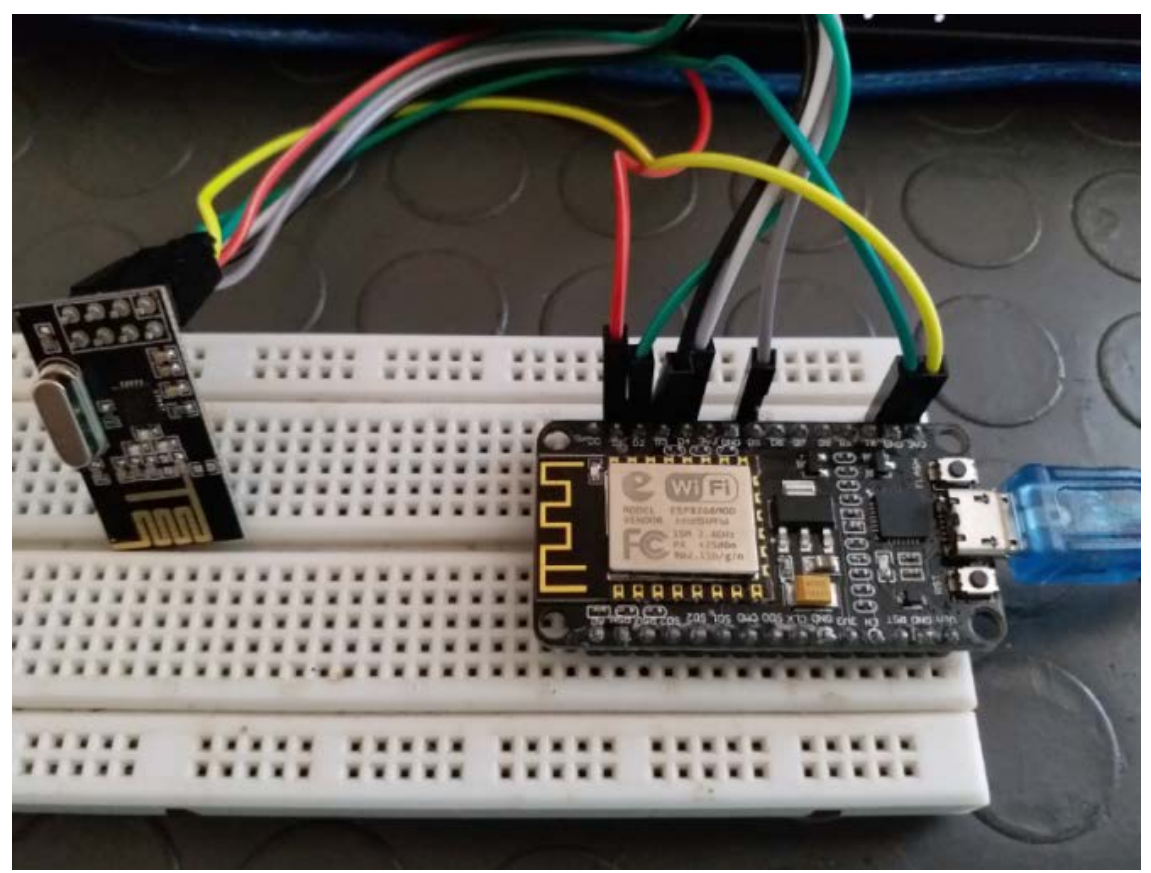

Fig. 9. NodeMCU controller and NRF24L01 RF module connection 
You can see the NodeMCU controller in Fig. 9. NodeMCU transmits the power values, received from Power Measurement and Controlling Module with RF, to Blynk server via Wi-Fi network. These power values are then transmitted to SEM interface via Blynk server. NodeMCU uses only NRF24L01 RF module, as the external hardware. It does not require any other external hardware.

\section{Results and Discussion}

Thanks to the SEM application installed in the Android device, the system-related data is continuously received from Blynk server. The data flow between SEM interface and NodeMCU is bi-directional, and it provide the opportunity to on/off the devices, along with displaying such data as Blynk interface current, voltage, instantaneous power and energy consumption. In Fig. 10, you can see the user panels for (a) washing machine, (b) dish washer, (c) air conditioner and (d) furnace that are within the SEM interface.

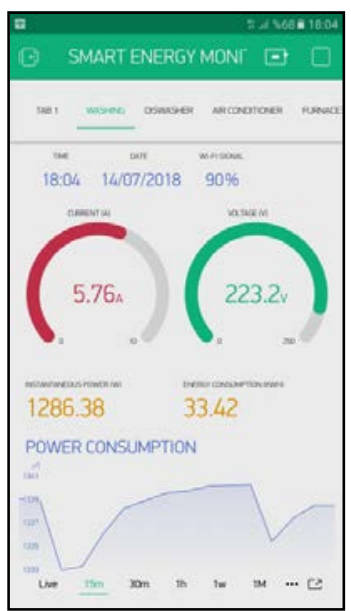

(a)

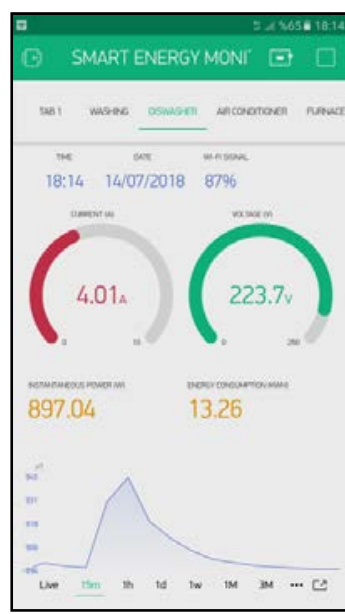

(b)

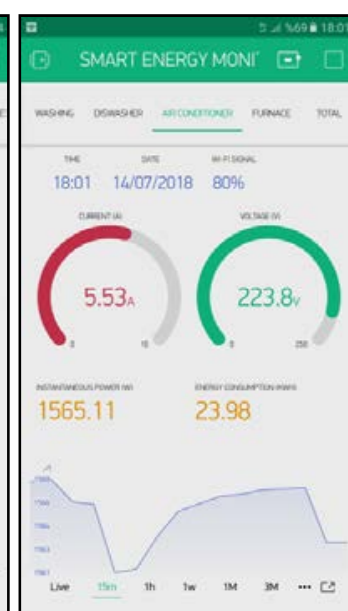

(c)

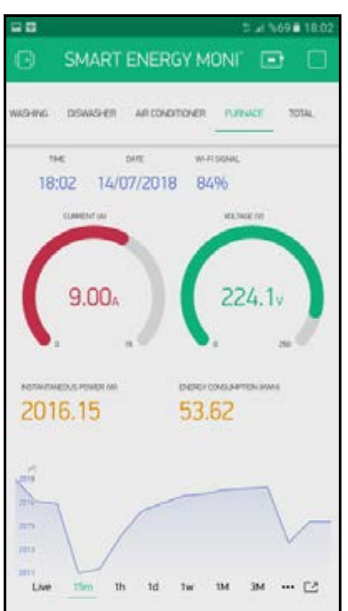

(d)

Fig. 10. The user panels for SEM interface:

a) Washing machine b) Dish washer c) Air Conditionerd) Furnace

Such data as the instantaneous power changes and energy consumption, received for each device owing to SEM interface, can be displayed graphically between a time range of 15 minutes to 1 year. Following the analysis of these graphics, it will be possible to take the required measures for reducing the energy consumption of the household. 


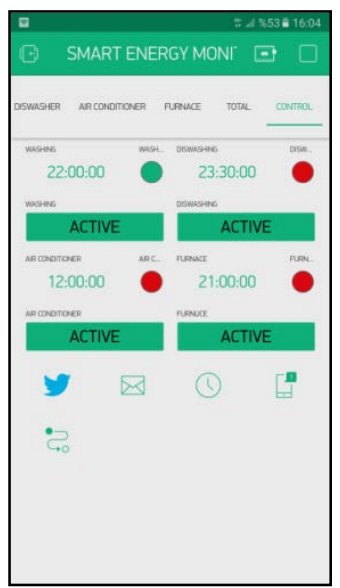

(a)

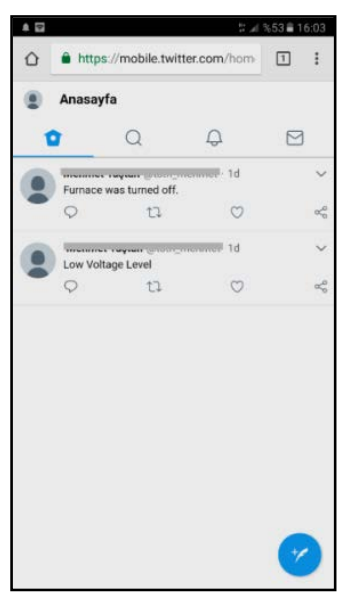

(b)

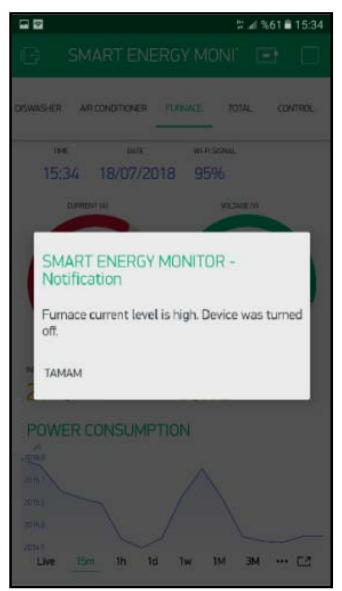

(c)

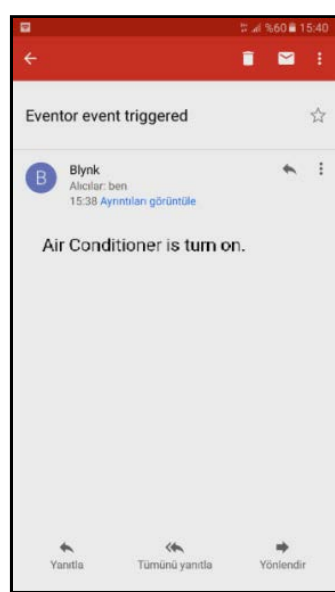

(d)

Fig. 11. (a) Control interface for electrical devices, (b) twitter notification (c) Blynk notification, (d) e-mail notification

In Fig. 11a, you can see the control interface of the devices that are located on SEM. Thanks to this interface, the devices can be operated within the intended periods of time by being programmed. The devices programmed as per the time zone are displayed as "ACTIVE" on the interface, while displaying those that are not programmed, thus optionally operating, as "PASSIVE". The status LED for each device indicates the instantaneous operational status. SEM interface sends notifications to the user concerning the devices by using various notification channels like e-mail, twitter. These notifications may involve the current, voltage, power, energy consumption values, ON-OFF status, etc. based on the user's intention. In Fig. 11b, you can see the notification examples received by the users via twitter; Fig. 11c via SEM interface display and Fig. 11d via e-mail. The graphic in Fig. 12 shows the average data of monthly consumption before using system SEM. During this period, the residents of the house have consumed energy due to their general tendencies.

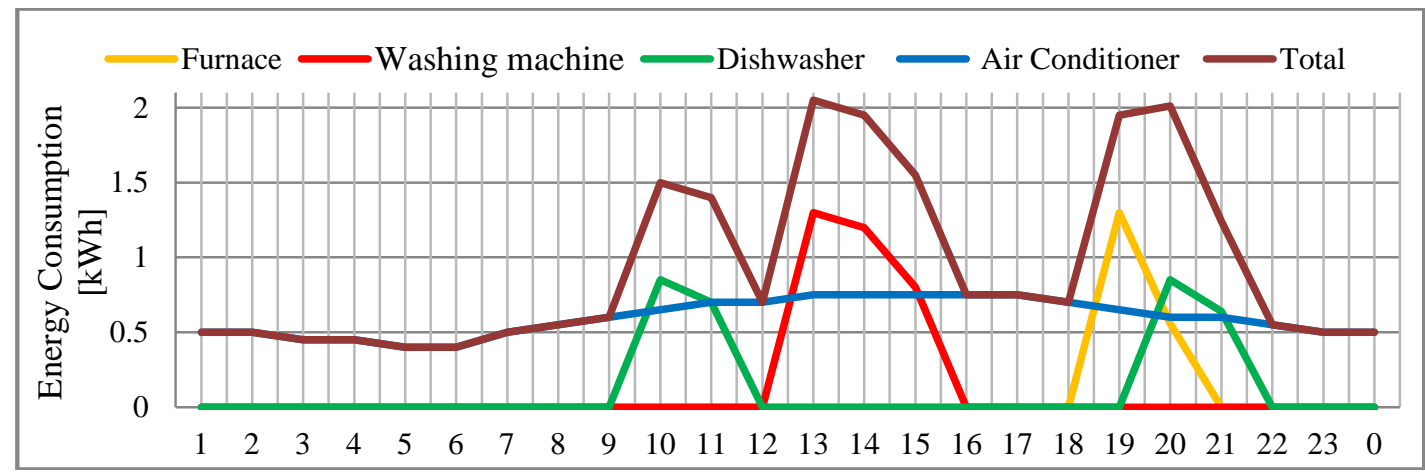

Fig. 12. Daily average energy consumption before using the SEM system.

The graph in Fig. 13 shows the monthly energy consumption and total energy consumption of the devices used for the month before the SEM system was used. 


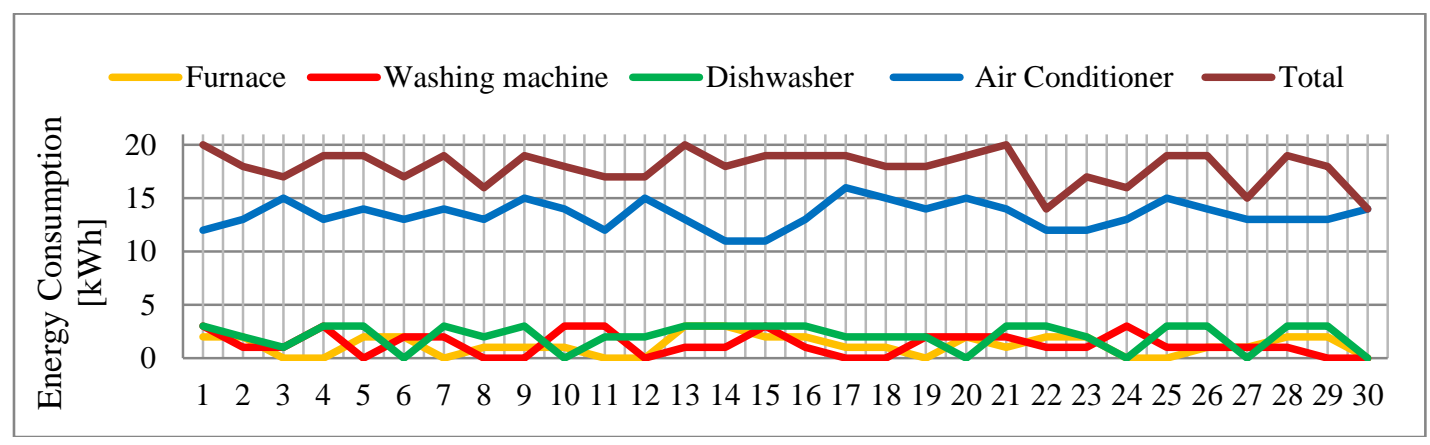

Fig. 13. Monthly energy consumption before using SEM system.

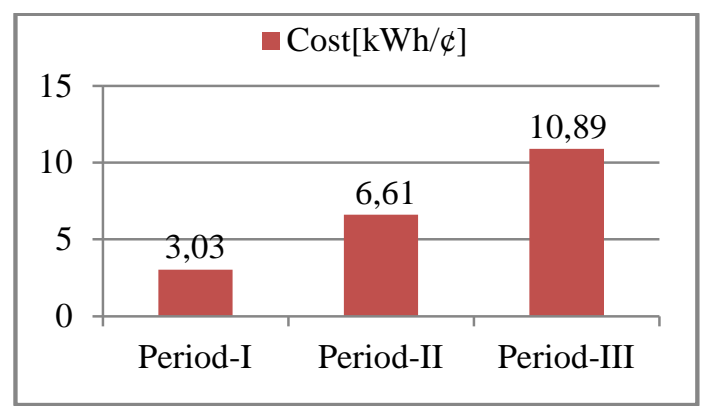

Fig. 14. Costs for energy periods.

In our country there are 3 charging periods for 3 different time periods in order to decrease energy costs and provide a balanced consumption of energy. In Fig. 14, the charging for this periods are shown. Period I refers between 22.00-06.00, Period II refers between 06.00-17.00 and Period III refers between 17.00-22.00. Being the cheapest, Period I cost 3.03 cent $/ \mathrm{kWh}$, Period II cost 6.60 cent $/ \mathrm{kWh}$ and the most expensive one, period III cost 10.89 cent $/ \mathrm{kWh}$. As understood, the most important thing in order to reduce the total consumption cost is to reduce the consumption in Period II, when demand of energy is the highest.

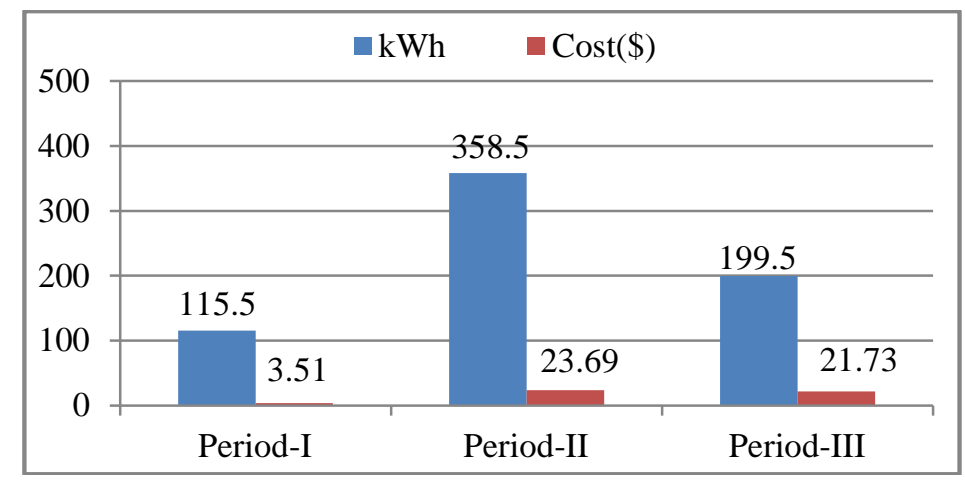

Fig. 15. Monthly energy consumption cost before using the SEM system.

In Fig. 15 energy consumption and energy costs of the mount before using the system SEM. The consumers have consumed energy due to their general tendencies and they used $673 \mathrm{kWh}$ energy with a cost of $\$ 48,92$ for a mount. 


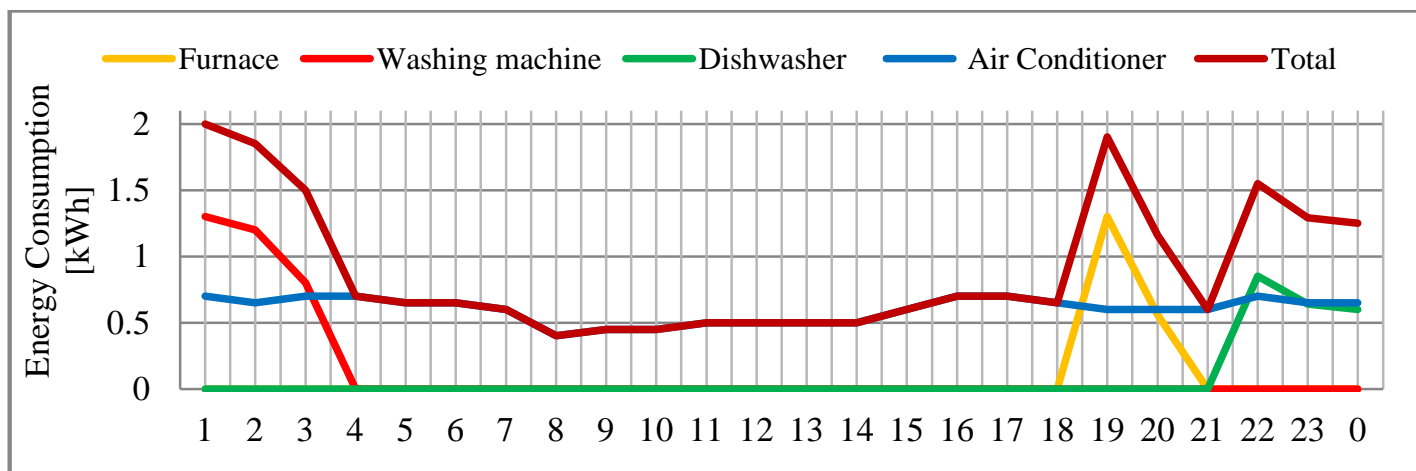

Fig. 16. Daily average energy consumption using the SEM system.

In Fig. 16 the daily average consumption value for each device after a monthly use of SEM system. The system guides consumer about choosing the right period for devices such as washing machine and dishwasher that have flexibility of the use during the day. That can be used any time throughout the day. In this way SEM system guides the use of devices to the period with low energy cost. For devices such as air-conditioner, which is to be used continuously during the day, the energy cost can be reduced by using the device with high performance at the low cost period. The SEM system can warn the users about that with user interface. In Fig. 17 monthly energy consumption graphic using SEM is given.

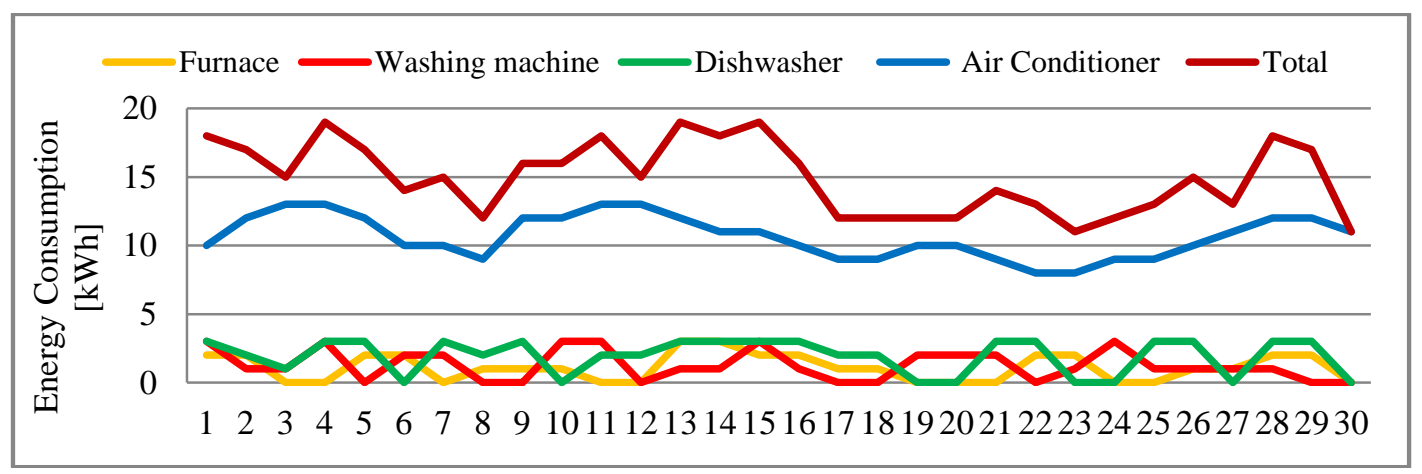

Fig. 17. Monthly energy consumption using the SEM system.

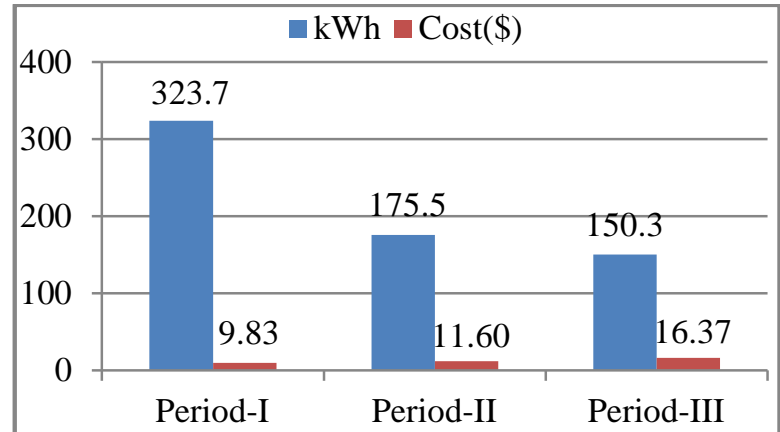

Fig. 18. Monthly energy consumption cost using the SEM system. 
Monthly energy consumption and energy cost using the SEM system is given in Fig. 18. In this period of using SEM, total energy consumption is $649 \mathrm{kWh}$ and energy cost is $\$ 37,79$.

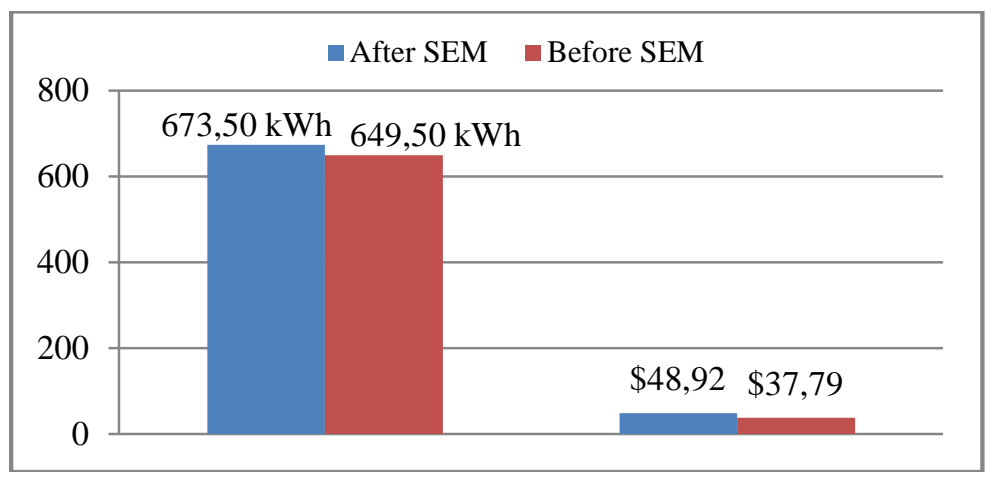

Fig. 19. Energy consumption and energy costs before and after the SEM system.

Total energy consumption and energy cost for the month before using SEM and total energy and consumption cost for the period using SEM is shown in Fig. 19. Comparing two period; the energy cost is $7.26 \mathrm{cent} / \mathrm{kWh}$ for the month that SEM is not used whereas it is 5.82 cent $/ \mathrm{kWh}$ for the month using SEM. Considering all these results it is clear that SEM system is efficient for reducing energy cost.

\section{Conclusions}

In this study, an IoT based SEM system has been designed by considering UC in order to reduce energy consumption and unit energy cost. Owing to the IoT based SEM system, the user is instantly provided with such information as current, voltage, power and energy consumption values. With this system, the energy costs can be reduced by operating such devices as washing machine and dish washer with the flexibility to be used during any time of the day, within the hours when the power costs are lower. Additionally, the energy consumption reports can be drawn up for each device as daily, weekly, monthly and annually. In this way, it will be easier to take the required measure for contributing in the energy saving by carrying out analyses on the energy consumption. The system provides the user with the opportunity to monitor and control the devices in his/her home via internet, as well. It also sends notifications to users via e-mail and twitter with regards to the failure information that are defined over the system. Where the devices operate out of the nominal operational value range, it de-activates the respective device, thus ensuring protection. SEM system guides the users to use the devices that are flexible to use at any time throughout the day, in Period I. SEM system transfers momentary using information via user interface and helps the users for taking energy saving measures. The system in this study, which is designed for just 4 devices, has the groundwork for all electrical home devices. Monthly using analysis shows that the system provides approximately $20 \%$ saving for unit energy cost. Thanks to SEM system, the average monthly energy cost on a was decreased from 7.26 cents/kwh to 5.82 cents/kwh. In this exemplary application, where UC is maintained, a monthly saving of 24 kwh energy and $\$ 11.13$ cost savings has been achieved. In addition, thanks to the proposed SEM system, the working hours of electrical household appliances with flexible working hours shifted to Period-I, when the demand for load is low, and a significant decrease has occurred in PAR. The next study will focus on a SEM system that can measure and control all household electrical appliances from a single center in order to reduce the energy consumption. 


\section{References}

[1] Ashton, Kevin, “That 'internet of things' thing," RFID journal, vol 22, no.7, pp. 97-114, 2009. Article (CrossRef Link).

[2] Gubbi, J., Buyya, R., Marusic, S. and Palaniswami, M., "Internet of Things (IoT): A vision, architectural elements, and future directions," Future generation computer systems, vol. 29, no. 7, pp.1645-1660, 2013. Article (CrossRef Link).

[3] Evans, Dave, "The internet of things: How the next evolution of the internet is changing everything,” CISCO, Int. J. Internet, vol. 3, no. 2, pp.123-132, 2011. Article (CrossRef Link).

[4] Zanella, A., Bui, N., Castellani, A., Vangelista, L. and Zorzi, M., "Internet of things for smart cities," IEEE Internet of Things journal, vol. 1, no. 1, pp. 22-32, 2014. Article (CrossRef Link).

[5] Yun, Miao, and Bu Yuxin, "Research on the architecture and key technology of Internet of Things (IoT) applied on smart grid," in Proc. of Advances in Energy Engineering (ICAEE), International Conference on. IEEE, 2010. Article (CrossRef Link).

[6] Harper, Richard, ed., "Inside the smart home," Springer Science \& Business Media, 2006. Article (CrossRef Link).

[7] Piyare, Rajeev, "Internet of things: ubiquitous home control and monitoring system using android based smart phone," International Journal of Internet of Things, vol. 2, no. 1, pp. 5-11, 2013. Article (CrossRef Link).

[8] Khan, Murad, Bhagya Nathali Silva, and Kijun Han, "Internet of things based energy aware smart home control system,” IEEE Access, vol. 4, pp. 7556-7566, 2016. Article (CrossRef Link).

[9] Ram, K. S. S., and A. N. P. S. Gupta, "IoT based Data Logger System for weather monitoring using Wireless sensor networks," International Journal of Engineering Trends and Technology (IJETT), vol. 32, pp. 71-75, 2016. Article (CrossRef Link).

[10] Shrouf, Fadi, and Giovanni M., "Energy management based on Internet of Things: practices and framework for adoption in production management," Journal of Cleaner Production, vol. 100, pp. 235-246, 2015. Article (CrossRef Link).

[11] Kansara, K., Zaveri, V., Shah, S., Delwadkar, S., and Jani, K., "Sensor based Automated Irrigation System with IOT: A Technical Review," International Journal of Computer Science and Information Technologies, vol. 6, no. 6, 2015. Article (CrossRef Link).

[12] Zagan, I., Gaitan, V. G., Petrariu, A. I., and Brezulianu, A., "Healthcare IoT m-GreenCARDIO remote cardiac monitoring system--concept, theory of operation and implementation," Advances in Electrical and Computer Engineering, vol. 17, no .2, pp. 23-31, 2017. Article (CrossRef Link).

[13] Im, H., Lee, S., Naqi, M., Lee, C., and Kim, S., "Flexible PI-Based Plant Drought Stress Sensor for Real-Time Monitoring System in Smart Farm,” Electronics, vol. 7, no. 7, pp.114, 2018. Article (CrossRef Link).

[14] Gungor, V. C., Sahin, D., Kocak, T., Ergut, S., Buccella, C., Cecati, C. and Hancke, G. P., "Smart grid technologies: Communication technologies and standards," IEEE transactions on Industrial informatics, vol. 7, no. 4, pp. 529-539, 2011. Article (CrossRef Link).

[15] Hu, M., Xiao, J. W., Cui, S. C., and Wang, Y. W., "Distributed real-time demand response for energy management scheduling in smart grid," International Journal of Electrical Power \& Energy Systems, vol. 99, pp. 233-245, 2018. Article (CrossRef Link).

[16] Ejaz, W., Naeem, M., Shahid, A., Anpalagan, A., and Jo, M., "Efficient energy management for the internet of things in smart cities,” IEEE Com. Magazine, vol. 55, no. 1, pp. 84-91, 2017. Article (CrossRef Link).

[17] Hussain, H. M., Javaid, N., Iqbal, S., Hasan, Q. U., Aurangzeb, K., and Alhussein, M., “An Efficient Demand Side Management System with a New Optimized Home Energy Management Controller in Smart Grid,” Energies, vol. 11, no. 1, pp. 190, 2018. Article (CrossRef Link).

[18] Shakeri, M., Shayestegan, M., Reza, S. S., Yahya, I., Bais, B., Akhtaruzzaman, K., Sopian, K., and Amin, N., "Implementation of a novel home energy management system (HEMS) architecture with solar photovoltaic system as supplementary source," Renewable Energy, vol. 125, pp. 108-120, 2018. Article (CrossRef Link). 
[19] Lu, X., Zhou, K., Chan, F. T., and Yang, S., “Optimal scheduling of household appliances for smart home energy management considering demand response,” Natural Hazards, vol. 88, no. 3, pp. 1639-1653, 2017. Article (CrossRef Link).

[20] Roselund, C., and Bernhardt, J., "Lessons learned along europe’s road to renewables," IEEE Spectrum, vol. 4, 2015. Article (CrossRef Link).

[21] Ma, R., Chen, H.H., Huang, Y.R., and Meng, W., "Smart grid communication: Its challenges and opportunities,” IEEE Trans. Smart Grid, vol. 4, pp. 36-46, 2013. Article (CrossRef Link).

[22] Al-Hassan, E., Shareef, H., Islam, M. M., Wahyudie, A., and Abdrabou, A. A., "Improved Smart Power Socket for Monitoring and Controlling Electrical Home Appliances,” IEEE Access, vol. 6, pp. 49292-49305, 2018. Article (CrossRef Link).

[23] Chellamani, G. K., and Chandramani, P. V., "Demand Response Management System with Discrete Time Window using Supervised Learning Algorithm,” Cognitive Systems Research, vol. 57, pp. 131-138, 2019. Article (CrossRef Link).

[24] Yoon, S. H., Kim, S. Y., Park, G. H., Kim, Y. K., Cho, C. H., and Park, B. H., "Multiple power-based building energy management system for efficient management of building energy," Sustainable Cities and Society, vol. 42, pp. 462-470, 2018. Article (CrossRef Link).

[25] Khalid R., Nadeem J., Muhammad H. R.,Sheraz A. and Arshad S., "Fuzzy energy management controller and scheduler for smart homes,” Sustainable Computing: Informatics and Systems, vol. 21, pp. 103-118, 2019. Article (CrossRef Link).

[26] Rahim, S., Javaid, N., Ahmad, A., Khan, S. A., Khan, Z. A., Alrajeh, N., and Qasim, U., "Exploiting heuristic algorithms to efficiently utilize energy management controllers with renewable energy sources,” Energy and Buildings, vol. 129, pp. 452-470, 2016. Article (CrossRef Link).

[27] Al-Ali, A.R., Zualkernan, I.A., Rashid, M., Gupta, R., and Alikarar, M., “A smart home energy management system using IoT and big data analytics approach,” IEEE Trans. Consum. Electron., vol. 63, no. 4, pp. 426-434, 2017. Article (CrossRef Link).

[28] Javaid, N., Javaid, S., Abdul, W., Ahmed, I., Almogren, A., Alamri, A., and Niaz, I.A., “A hybrid genetic wind driven heuristic optimization algorithm for demand side management in smart grid,” Energies , vol. 10, no. 3, pp. 319, 2017. Article (CrossRef Link).

[29] Ahmed, M.S., Mohamed, A., Khatib, T., Shareef, H., Homod, R.Z., and Ali, J.A., "Real time optimal schedule controller for household energy management system using new binary backtracking search algorithm,” Energy Build., vol. 138, pp. 215-227, 2017. Article (CrossRef Link).

[30] Rasheed, M. B., Javaid, N., Ahmad, A., Khan, Z. A., Qasim, U., and Alrajeh, N., “An efficient power scheduling scheme for residential load management in smart homes," Applied Sciences, vol. 5, no. 4, pp. 1134-1163, 2015. Article (CrossRef Link).

[31] Wen, Z., O’Neill, D., and Maei, H., "Optimal demand response using device-based reinforcement learning,” IEEE Transactions on Smart Grid, vol. 6, no. 5, pp. 2312-2324, 2015. Article (CrossRef Link).

[32] Basit, A., Sidhu, G. A. S., Mahmood, A., and Gao, F., "Efficient and autonomous energy management techniques for the future smart homes," IEEE Transactions on Smart Grid, vol. 8, no. 2, pp. 917-926, 2017. Article (CrossRef Link).

[33] Joo, I. Y., and Choi, D. H., "Distributed optimization framework for energy management of multiple smart homes with distributed energy resources,” IEEE Access, vol. 5, pp. 15551-15560, 2017. Article (CrossRef Link).

[34] Khan, M. A., Javaid, N., Mahmood, A., Khan, Z. A., and Alrajeh, N., “A generic demand side management model for smart grid,” International Journal of Energy Research, vol. 39, no. 7, pp. 954-964, 2015. Article (CrossRef Link).

[35] https://www.allegromicro.com/ /.../acs712-datasheet.ashx (access on 27.09.2018) 


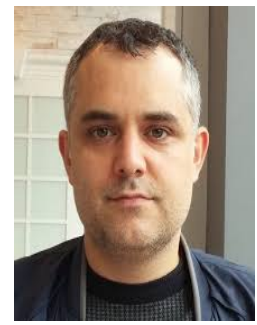

Mehmet TAŞTAN, was born in Afyon, Turkey, in 1977. He received the M.S. degrees in electric and electrical engineering from the University of Niğde Ömer Halisdemir, in 2002 and the Ph.D. degree in electric and electrical engineering from Sakarya University, in 2014. Now he is a Assistant Professor in the Department of Electronic and Automation, University of Manisa Celal Bayar, Manisa, Turkey. His studies include harmonic analysis in power systems, power quality, embedded systems and signal processing. 